\title{
PENGARUH EARNING PER SHARE, TOTAL ASSETS TURN OVER DAN PERTUMBUHAN PENJUALAN TERHADAP HARGA SAHAM PADA PERUSAHAAN SEKTOR PROPERTY AND REAL ESTATE YANG TERDAFTAR DI BURSA EFEK INDONESIA
}

\section{THE EFFECT OF EARNING PER SHARE, TOTAL TURN OVER ASSETS AND SALES GROWTH ON STOCK PRICES IN PROPERTY AND REAL ESTATE SECTOR COMPANIES THAT ARE REGISTERED IN INDONESIAN STOCK EXCHANGE}

\author{
Debora Silitonga ${ }^{1}$, Putri Delima S.I Siregar ${ }^{2}$, Rijal Siahaan $^{3}$, \\ Andi Pranata Ginting ${ }^{4}$, Rosmita Sari Siregar ${ }^{5}$ \\ Universitas Prima Indonesia, Medan ${ }^{1,2,3,4,5}$. \\ deborasilitionga97@gmail.com ${ }^{1}$
}

Submit, 18-05-2019 Accepted,23-06-2019 Publish,23-06-2019

\begin{abstract}
The stock price is the price of a stock that occurs on the stock market, at a certain time determined by the market actor and determined by the demand and supply of the shares concerned in the capital market. This study aims to examine the effect of earnings per share, total asset turn over and sales growth on stock prices in the property and real estate sector companies listed on the Indonesia Stock Exchange (IDX). The population in this study was 47 companies and made a sample of 21 companies with purposive sampling technique. This study uses multiple linear regression analysis. The results of simultaneous research have an effect on stock prices. Partially earnings per share has a significant effect on stock prices, while total asset turnover and sales growth have no significant effect on stock prices. Simultaneously earnings per share, total assets turn over and sales growth have a significant effect on stock prices.
\end{abstract}

Keywords: Earning Per Share, Total Assets Turn Over, Sales Growth, Stock Price

\begin{abstract}
ABSTRAK
Harga saham merupakan harga suatu saham yang terjadi yang terjadi di pasar bursa, pada saat tertentu yang ditentukan oleh pelaku pasar dan di tentukan oleh permintaan dan penawaran saham yang bersangkutan di pasar modal. Penelitian ini bertujuan untuk menguji pengaruh earning per share,total aset turn over dan pertumbuhan penjualan terhadap harga saham pada perusahaan sektor property and real estate yang terdaftar di Bursa Efek Indonesia (BEI). Populasi dalam penelitian ini adalah 47 perusahaan dan di jadikan sampel 21 perusahaan dengn teknik purposive sampling. Penelitian ini menggunakan analisis regresi linier berganda. Hasil penelitian simultan berpengaruh terhadap harga saham. Secara parsial earning per share berpengaruh signifikan terhadap harga saham, sedangkan total asset turn over dan pertumbuhan penjualan tidak berpengaruh signifikan terhadap harga saham. Secara simultan earning per share, total assets turn over dan pertumbuhan penjualan berpengaruh signifikan terhadap harga saham.

Kata Kunci : Earning Per Share, Total Assets Turn Over, Pertumbuhan Penjualan, Harga Saham.
\end{abstract}


PENDAHULUAN

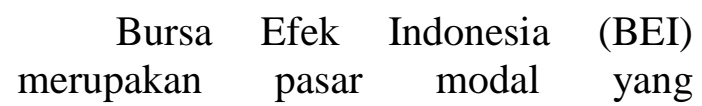
memperjualbelikan instrument keuangan jangka panjang seperti saham, obligasi dan berbagai produk lainnya dalam bentuk utang maupun modal sendiri. Bursa efek juga merupakan salah satu bursa efek yang cepat perkembangannya sehingga menjadi alternatif yang disukai perusahaan untuk mencari dana. Perkembangan bursa efek dapat dilihat dengan semakin banyaknya anggota bursa,juga dapat dilihat dari perubahan harga saham yang diperdagangkan (Wijaya, 2017).

Salah satu sektor yang terdaftar di Bursa Efek Indonesia adalah sektor property dan real estate yang merupakan perusahaan yang mengalami perkembangan yang sangat pesat dan dianggap menjadi pilihan utama dalam melakukan investasi. Jika EPS tinggi maka investor akan menilai bahwa emiten memiliki kinerja yang baik. Total assets turn over mengukur kemampuan perusahaan memaksimalkan seluruh harta perusahaan dalam menhasilkan penjualan. Pertumbuhan penjualan menjadi ukuran penting mengenai besarnya suatu pendapatan perusahaan dan menjadi acuan dalam menilai keberhasilan suatu perusahaan dalam menjual produknya. Harga saham dipengaruhi oleh keinginan pembeli atau penjual.Sebaiknya perusahaan setiap saat memberi informasi yang cukup ke bursa efek, sepanjang informasi tersebut berpengaruh terhadap harga sahamnya. Pada tahun pada tahun 2012 sebesar 6.266.533.661 lembar dan memperoleh closing price sebesar Rp.610. Pada tahun 2013 jumlah saham beredar mengalami kenaikan sebesar 12.533.067.322 lembar namun closing price mengalami penurunan sebesar Rp.390. tahun 2012 total aktiva sebesar
Rp. 886.378.756.878 dan memperoleh closing price sebesar Rp.140. Pada tahun 2013 total aktiva mengalami kenaikan sebesar Rp. 938.536.950.089 namun closing price mengalami penurunan sebesar Rp.111. tahun 2014 penjualan sebesar Rp. 154.187.673.595 dan memperoleh closing price sebesar Rp.51. Pada tahun 2015 penjualan mengalami penurunan sebesar Rp. 119.810.618.136 namun closing price mengalami kenaikan sebesar sebesar Rp.55.

Menurut Murhadi (2013), Earning Per Share adalah pendapatan per lembar saham yang dapat diilihat di laporan laba rugi. Menurut Kasmir (2012), rasio yang rendah berarti manajemen belum berhasil untuk memuaskan pemegang saham, sebaliknya dengan rasio yang tinggi, kesejahteraan pemegang saham meningkat. Menurut Kodrat dan Indonanjaya (2010), hubungan harga saham seharusnya (nilai intrinsik) dengan earning per share (EPS), yaitu semakin besar pendapatan per lembar saham, semakin besar harga dari saham. Adapun rumus Earning Per Share adalah :

$$
\text { EPS }=\frac{\text { Laba Bersih }}{\text { Jumlah Saham Beredar }}
$$

Menurut Murhadi (2013), Total
Asset Turn Over menunjukkan efektivitas perusahaan yang menggunakan asetnya untuk menghasilkan pendapatan. Menurut Syamsuddin (2013) semakin tinggi ratio total assets turn over berarti semakin efisien penggunaan keseluruhan aktiva di dalam menghasilkn penjualan. Menurut Kasmir (2012), rumus yang digunakan untuk mencari total assets turn over adalah sebagai berikut:

$$
\text { TATO }=\frac{\text { penjualan }(\text { sales })}{\text { Total Aktiva }(\text { Total Assets })}
$$


Menurut Fahmi (2012), rasio pertumbuhan yaitu rasio yang mengukur seberapa besar kemampuan perusahaan dalam mempertahankan posisinya di dalam industri dan dalam perkembangan ekonomi secara umum. Menurut Sartono (2010) perusahaan dengan penjualan yang relatif stabil berarti memiliki aliran kas yang relatif stabil pula, maka dapat menggnakan utang lebih besar daripada perusahaan dengan penjualan yang tidak stabil. Menurut Brigham dan Houston (2012) tingkat pertumbuhan yang negatif menunjukkan perusahaan yang sedang menurun. Hal ini akan menyebabkan kerugian modal dan bukan keuntungan modal. Sudah pasti, harga saham perusahaan yang sedang menurun relatif rendah, dan imbal hasil devidennya harus cukup tinggi untuk menutupi kerugian modal yang diharapkan dan masih menghasilkan total pengembalian yang kompetitif. Menurut Harahap (2015) rumus untuk mencari pertumbuhan penjualan adalah sebagai berikut:

Pertumbuhan Penjualan

$=\frac{\text { Penjualan Tahun Ini }- \text { Penjualan Tahun Lalu }}{\text { Penjualan Tahun Lalu }}$

Menurut Fahmi (2015), saham adalah tanda bukti penyertaan kepemilikan modal/dana pada suatu perusahaan. Menurut Najib (2015) harga yang tepat. Harga saham mencerminkan semua informasi yang ada di masyarakat sehubungan dengan nilai perusahaan. Rumus untuk mencari harga saham adalah sebagai berikut :

Close atau closing price menunjukkan harga penutupan suatu saham.Berdasarkan teori yang dijelaskan, maka peneliti mengemukakan hipotesis sebagai berikut:

H1 : Earning per share (EPS) berpengaruh secara parsial terhadap harga saham pada perusahaan property dan real estate yang terdaftar di Bursa Efek Indonesia tahun 2012-2016.

H2 : Total assets turn over (TATO) berpengaruh secara parsial terhadap harga saham pada perusahaan property dan real estate yang terdaftar di Bursa Efek Indonesia tahun 2012-2016.

H3 : Pertumbuhan penjualan berpengaruh secara parsial terhadap harga saham pada perusahaan property dan real estate yang terdaftar di Bursa Efek Indonesia tahun 2012-2016.

H4: Earning per share (EPS), total assets turn over (TATO) dan pertumbuhan penjualan berpengaruh secara simultan terhadap harga saham pada perusahaan property dan real estate yang terdaftar di Bursa Efek Indonesia tahun 2012-2016.

\section{METODE PENELITIAN}

Dalam penelitian ini, peneliti menggunakan data sekunder. Data sekunder merupakan sumber yang tidak langsung memberikan data kepada pengumpul data, misalnya lewat orang lain atau lewat dokumen. Pada penelitian ini menggunakan pendekatan penelitiannya adalah penelitian kuantitatif. metode penelitian kuantitatif dapat diartikan sebagai metode positivistik karena berlandaskan pada filsafat positivisme. Metode ini disebut metode kuantitatif karena data penelitian berupa angka-angka dan analisis menggunakan statistik.

Populasi adalah wilayah generalisasi yang terdiri atas obyek/subyek yang mempunyai kualitas dan karakteristik tertentu yang ditetapkan oleh peneliti untuk selanjutnya ambil kesimpulannya (Sugiyono 2017). Populasi dalam penelitian ini adalah 47 perusahaan sektor property dan real estate yang terdaftar di Bursa Efek Indonesia tahun 2012-2016. 
Sampel adalah bagian dari jumlah dan karakteristik yang dimiliki oleh populasi tersebut (Sugiyono 2017). perusahaan yang dijadikan sampel penelitian adalah 21 perusahaan, dengan waktu pengamatan selama 5 tahun jadi total sampel pengamatan adalah $21 \times 5$ $=105$. Model penelitian yang digunakan adalah dengan menggunakan analisis regresi linear berganda. Model regresi linear berganda yang digunakan adalah sebagai berikut:

$$
Y=a+b_{1} X_{1}+b_{2} X_{2}+b_{3} X_{3}+e
$$

Keterangan:

Y : Harga Saham

a : Konstanta

$\mathrm{b}_{1}$ : Koefisien regresi variabel $\mathrm{X}_{1}$

(earning per share)

$\mathrm{b}_{2}$ : Koefisien regresi variabel $\mathrm{X}_{2}$ (total assets turn over)

$b_{3}$ : Koefisien regresi variabel $X_{3}$ (pertumbuhan penjualan)

$\mathrm{X}_{1}$ : variabel Earning Per Share

$\mathrm{X}_{2}$ : variabel Total Assets Turn Over

$X_{3}$ : variabel Pertumbuhan Penjualan

e : $\operatorname{error}(5 \%)$

\section{HASIL DAN PEMBAHASAN}

Analisis regresi linier berganda

Pengujian hipotesis yang digunakan dalam penelitian adalah dengan menggunakan analisis regresi linear berganda.

\section{Tabel 1}

\section{Regresi Linear Berganda}

Coefficients $^{\mathrm{a}}$

\begin{tabular}{|c|c|c|c|c|c|}
\hline \multirow{2}{*}{\multicolumn{2}{|c|}{ Model }} & \multicolumn{2}{|c|}{$\begin{array}{l}\text { Unstandardize } \\
\text { d Coefficients }\end{array}$} & \multirow[t]{2}{*}{$\mathrm{T}$} & \multirow[t]{2}{*}{ Sig. } \\
\hline & & $\overline{\mathrm{B}}$ & $\begin{array}{l}\text { Std. } \\
\text { Error }\end{array}$ & & \\
\hline \multirow{4}{*}{1} & (Constant) & 4.277 & .674 & 6.346 & .000 \\
\hline & LN_EPS & .430 & .093 & 4.628 & .000 \\
\hline & $\overline{\text { LN_TATO }}$ & -.170 & .325 & -.523 & .602 \\
\hline & $\overline{\text { LN_PP }}$ & -.038 & .113 & -.335 & .738 \\
\hline
\end{tabular}

Penjelasan dari nilai persamaan rumus pada unstandardized coefficients tersebut dapat dijelaskan

1. Nilai konstanta sebesar 4,277. Nilai konstanta ini menunjukkan bahwa apabila nilai variabel bebas yaitu earning per share, total assets turn over dan pertumbuhan penjualan dianggap konstanta 0 , harga saham maka (Y) sebesar 4,277.

2. Nilai koefisien regresi earning per share (X1) sebesar 0,430 bertanda positif (+). Hasil penelitian menunjukkan jika kenaikan 1 kali earning per share maka akan meningkat harga saham sebesar 0,430 dengan asumsi semua variabel independen dianggap nol.

3. Nilai koefisien regresi total assets turn over (X2) sebesar -0,170 bertanda negatif (-). Hasil penelitian menunjukkan jika kenaikan 1 kali total assets turn over maka akan menurunkan harga saham sebesar $-0,170$.

4. Nilai koefisien regresi pertumbuhan penjualan sebesar $-0,030$ bertanda negatif (-). Hasil penelitian menunjukkan jika kenaikan 1 kali Kenaikan pertumbuhan penjualan maka akan menurunkan harga saham sebesar $-0,030$.

\section{Uji Parsial (Uji t)}

Pengujian hipotesis secara parsial atau uji $\mathrm{t}$ dilakukan untuk mengetahui hubungan antara variabelvariabel independen terhadap variabel dependen secara parsial.

\section{Tabel 2}

Hasil Uji Parsial (Uji T)

\begin{tabular}{llll}
\hline \multicolumn{3}{c}{ Coefficients $^{\mathbf{a}}$} \\
\hline \multicolumn{2}{l}{ Model } & $\mathrm{T}$ & Sig. \\
& & & \\
\hline \multirow{3}{*}{1} & (Constant) & 6.346 & .000 \\
\cline { 2 - 4 } & LN_EPS & 4.628 & .000 \\
\cline { 2 - 4 } & LN_TATO & -.523 & .602 \\
\cline { 2 - 4 } & LN_PP & -.335 & .738 \\
\hline
\end{tabular}

Sumber: Sumber pengolahan data SPSS 
Berdasarkan tabel diatas dapat disimpulkan bahwa:

1. Variabel earning per share secara parsial memiliki nilai $t_{\text {hitung }}$ sebesar 4,628 dan $t_{\text {tabel }} 1,98373$, maka $t_{\text {hitung }}>t_{\text {tabel }}$ dengan nilai signifikan $0,000<0,05$ hasil tersebut menunjukkan bahwa $\mathrm{H}_{\mathrm{o}}$ ditolak dan $\mathrm{H}_{\mathrm{a}}$ diterima artinya bahwa secara parsial earning per share berpengaruh positif dan signifikan terhadap harga saham.

2. Variabel total assets turn over terhadap harga saham nilai $t_{\text {hitung }}$ 0,523 dan $t_{\text {tabel }} 1,98373$, maka $t_{\text {hitung }}<t_{\text {tabel }}$ dengan tingkat signifikan $0,602>0,05$ hasil tersebut menunjukkan bahwa maka $\mathrm{H}_{\mathrm{o}}$ diterima dan $\mathrm{H}_{\mathrm{a}}$ ditolak artinya bahwa total assets turn over secara parsial tidak berpengaruh dan tidak signifikan terhadap harga saham.

3. Variabel pertumbuhan penjualan terhadap harga saham nilai $t_{\text {hitung }}$ 0,335 dan $t_{\text {tabel }}(1,98373)$ maka $t_{\text {hitung }}<t_{\text {tabel }}$ dengan tingkat signifikan $0,738>0,05$ hasil tersebut menunjukkan bahwa maka $\mathrm{H}_{\mathrm{o}}$ diterima dan $\mathrm{H}_{\mathrm{a}}$ ditolak artinya pertumbuhan penjualan secara parsial tidak berpengaruh dan tidak signifikan terhadap harga saham.

\section{Uji Simultan (Uji F)}

Pengujian secara simultan bertujuan untuk mengetahui ada tidaknya pengaruh variabel bebas secara bersama-sama terhadap variabel terikat. Untuk mengetahui apakah hipotesis yang diajukan diterima atau ditolak dilakukan dengan cara membandingkan nilai $F_{\text {hitung }}$ dengan $F_{\text {tabel }}$.

\section{Tabel 3}

Hasil Uji Simultan (Uji F)

\begin{tabular}{llllll}
\hline \multicolumn{4}{c}{ ANOVA $^{\mathbf{a}}$} \\
\hline Model & Df & $\begin{array}{l}\text { Mean } \\
\text { Square }\end{array}$ & F & Sig. \\
\hline 1 & $\begin{array}{l}\text { Regre } \\
\text { ssion }\end{array}$ & 3 & 11.608 & 7.296 & $.000^{\mathrm{b}}$ \\
\hline
\end{tabular}

\begin{tabular}{lll}
\hline $\begin{array}{l}\text { Resid } \\
\text { ual }\end{array}$ & 72 & 1.591 \\
\hline Total & 75 & \\
\hline
\end{tabular}

Sumber : Hasil Pengolahan Data SPSSHasil uji F yang ditampilkan tabel di atas menunjukkan bahwa nilai $F_{\text {hitung }}(7,296)$ dan dengan menggunakan tabel $\mathrm{F}$ adalah df = n(105)-k(3)-1 adalah 101 diperoleh nilai $F_{\text {tabel }}(2,69)$. Maka hasilnya adalah $F_{\text {hitung }}(7,296)>F_{\text {tabel }}(2,69)$ dengan tingkat signifikan $0,000<0,05$. Hal ini menunjukkan bahwa hasil hipotesis penelitian $\mathrm{H}_{\mathrm{a}}$ diterima dan $\mathrm{H}_{\mathrm{o}}$ ditolak, artinya variabel bebas earning per share, pertumbuhan penjualan dan total assets turn over secara simultan berpengaruh positif dan signifikan terhadap harga saham pada perusahaan property and real estate yang terdaftar di BEI tahun 2012-2016.

\section{Uji Koefisien Determinasi $\left(\mathbf{R}^{\mathbf{2}}\right)$}

Tujuan koefisien determinasi $\left(\mathrm{R}^{2}\right)$ adalah melihat sejauh mana variabel independen mampu menjelaskan variasi variabel dependen. Nilai koefisien determinasi digunakan untuk mengukur seberapa besar pengaruh earning per share, pertumbuhan penjualan, total assets turn over terhadap harga saham.

\section{Tabel 4}

Koefisien Determinasi

\begin{tabular}{llll}
\hline \multicolumn{4}{c}{ Model Summary $^{\mathrm{b}}$} \\
\hline Model & $\mathrm{R}$ & $\mathrm{R}$ & Adjusted \\
& & Square & R Square \\
& & & \\
\hline 1 & $.483^{\mathrm{a}}$ & .233 & .201
\end{tabular}

Sumber : Hasil Pengolahan Data SPSS

Berdasarkan tabel di atas uji koefisien determinasi menunjukkan Adjusted R Square sebesar 0,201, hal ini berarti $20,1 \%$ variasi harga saham dapat dijelaskan oleh earning per share, total assets turn over, pertumbuhan penjualan. Sedangkan sisanya sebesar 
79,9\% dijelaskan oleh variabel lainnya yang tidak terdapat dalam penelitian ini.

\section{PENUTUP}

\section{Kesimpulan}

Kesimpulan yang diambil dari penelitian ini adalah sebagai berikut:

1. Earning per share berpengaruh positif dan signifikan terhadap harga saham pada perusahaan sektor property and real estate yang terdaftar di Bursa Efek Indoonesia tahun 2012-2016.

2. Total assets turn over tidak berpengaruh dan tidak signifikan terhadap harga saham pada perusahaan sektor property and real estate yang terdaftar di Bursa Efek Indonesia tahun 2012-2016.

3. Pertumbuhan penjualan tidak berpengaruh dan tidak signifikan terhadap harga saham pada perusahaan sektor

4. Earning per share, total assets turn over dan pertumbuhan penjualan tidak berpengaruh dan tidak signifikan terhadap harga saham pada perusahaan sektor property and real estate yang terdaftar $\mathrm{di}$ Bursa Efek Indoonesia tahun 20122016.

\section{Saran}

Berdasarkan kesimpulan di atas dapat diberikan beberapa saran sebagai berikut:

1. Bagi peneliti selanjutnya, diharapkan menambah rasio keuangan lainnya sebagai variabel independen, dan menambah periode pengamatan sehingga hasil penelitian akan lebih baik.

2. Bagi perusahaan, pihak perusahaan harus terus menjaga dan meningkatkan eksistensinya sehingga dapat menarik minat investor untuk berinvestasi.
3. Bagi Universitas Prima Indonesia, agar lebih meningkatkan koleksi buku-buku dan jurnal yang relevan dengan penelitian ini dan untuk kedepannyadapat menjalin kerja sama dengan perusahaanperusahaan yang ada di area Medan agar mahasiswa dapat menggunakan perusahaan tersebut sebagai objek penelitian.

\section{DAFTAR PUSTAKA}

Brigham \& Houston. (2010). Dasardasar Manajemen Keuangan. Salemba Empat, editor, Jakarta: Salemba Empat.

Fahmi, Irham. (2012). Pengantar Manajemen Keuangan. Cetakan Keempat. Bandung: CV. Alfabeta. Harahap, Sofyan Syafri. (2015). Analisis Kritis Atas Laporan Keuangan. Cetakan Kedua belas. Jakarata: PT. RajaGrafindo Persada.

Kasmir. (2012). Analisis Laporan Keuangan. Cetakan Kelima. Jakarta: PT. Raja Grafindo Persada.

Kodrat, David S \& Kurniawan Indonanjaya. (2010). Manajemen Investasi Pendekatan Teknikal Dan Fundamental Untuk Analisis Saham. Cetakan Pertama. Yogyakarta: Graha Ilmu.

Murhadi, Werner R. (2013) .Analisis Laporan Keuangan, Proyeksi Dan Valuasi Saham. Rasyid A, editor, Jakarta: Salemba Empat.

Najib, Mohammad. (2015). Manajemen Keuangan. Cetaka Pertama. Bandung: CV. Pustaka Setia.

Sartono. (2010). Manajemen Keuangan Teori Dan Aplikasi. Cetakan Keempat. Yogyakarta: BPFEYogyakarta. 
Sugiyono. (2017). Metode Penelitian (Kuantitatiif, Kualitatif, dan $R \& D)$. Cetakan kedua puluh. Bandung: CV. Alfabeta.

Syamsuddin, Lukman. (2013). Manajemen Keuangan Perusahaan: Konsep Aplikasi DalamPerencanaan,

Pengawasan, Dan Pengambilan Keputusan. Cetaka Kedua belas. Jakarta: PT. RajaGrafindo Persada.

Wijaya, E. (2017). Pengaruh Rasio Likuiditas, Rasio Profitabilitas dan Rasio Pasar terhadap Kebijakan Dividen pada Perusahaan Rokok. Journal of Economic, Bussines and Accounting (COSTING), 1(1), 111. doi:10.31539/costing.v1i1.68 